\title{
CAPACIDAD PARASÍTICA DE HONGOS CONTRA EL NEMATODO DEL QUISTE DE LA PAPA (Globodera spp.)
}

\author{
Cristina Vargas Chacón ${ }^{1}$, Ricardo Piedra Naranjo ${ }^{1}$
}

\section{RESUMEN}

Capacidad parasítica de hongos contra el nematodo del quiste de la papa. El objetivo de este estudio fue evaluar la acción de hongos sobre el nematodo formador del quiste de la papa, con el fin de que sean usados en el manejo integrado del cultivo, en zonas donde se haya encontrado el nematodo. El estudio fue realizado durante el año 2010 en el Laboratorio de Servicios de Fitoprotección del INTA-Costa Rica. Quistes de Globodera spp fueron extraídos de un suelo proveniente de la provincia de Cartago, distrito de Alvarado a $9^{\circ} 58.5812^{\prime}$ latitud Norte y $83^{\circ} 49.7996^{\prime}$ longitud Oeste. Se estableció un diseño de bloques completos al azar con cinco tratamientos y cuatro repeticiones. Los hongos usados fueron Trichoderma spp, Beauveria bassiana, Paecilomyces lilacinus y Arthrobotrys spp. En los extremos de las placas petri se colocó el hongo con los quistes, los cuales, luego de aproximadamente 15 días se homogenizaron y se observaron al microscopio, donde se evidenció el parasitismo del hongo sobre los huevos del nematodo liberados, medido como porcentaje de parasitismo. Se realizó un análisis de varianza y se empleó una prueba de separación de medias mediante prueba de Duncan con un $95 \%$ de confianza. Se presentaron diferencias altamente significativas entre el porcentaje de parasitismo ( $P=0,0001)$. Globodera spp, fue parasitado en un $97 \%$ por $P$. lilacinus, superando estadísticamente a los tratamientos con Trichoderma spp y Arthrobotrys spp. Los porcentajes de parasitismo de B. bassiana, Trichoderma spp y Arthrobotrys spp fueron $93,6,88,2$ y $70,6 \%$ respectivamente, siendo estadísticamente diferentes al testigo. Todos los hongos evaluados tienen un potencial promisorio en el manejo de estadios inmaduros de Globodera spp; capacidad que debe ser evaluada en condiciones de campo.

Palabras clave: Globodera pallida, Globodera rostochiensis, control biológico, nematicidas, hongos nematófagos.

\section{INTRODUCCIÓN}

El nematodo formador del quiste de la papa (Globodera pallida), tiene su origen en las montañas de los Andes en Sur América, fue introducido a Europa a mediados del siglo XIX y se puede encontrar desde zonas ubicadas a nivel del mar hasta grandes altitudes. Su distribución va desde Asia, África, Europa y en toda América (Trifonova 2006). Este nematodo fue reportado por primera vez en Costa Rica en enero del 2005 por la Universidad de Costa Rica, en plantaciones de la variedad Floresta para semilla; ubicadas en las faldas del volcán
Irazú, específicamente en la comunidad La Pastora, Cantón de Alvarado de la Provincia de Cartago. Este hallazgo alertó a los productores y a las autoridades gubernamentales por su condición de plaga cuarentenaria y de gran impacto en la producción y exportación de papa (MAG 2006). El Ministerio de Agricultura y Ganadería, por medio del Servicio Fitosanitario del Estado (SFE), ha tomado una serie de medidas fitosanitarias para evitar que la plaga se disemine a otras áreas que al momento se diagnostican libres, se ha procedido a destruir semilla contaminada, declarar en cuarentena lotes de semilla 
afectada, evitar la movilización de maquinaria agrícola de fincas enfermas a sanas, usar semilla certificada e instruir a los productores sobre la metodología de combate mediante la programación de charlas. Sin embargo estas acciones han originado grandes pérdidas económicas a los agricultores de zonas afectadas.

El daño causado, relacionado principalmente al peso de los tubérculos, está relacionado al número de huevos de nematodo por unidad de suelo. Se estima que aproximadamente se pierden 2 t/ha de papa por cada 20 huevos/g de suelo; lo que significa que se puede alcanzar más del $80 \%$ en pérdida del cultivo, cuando la población de nematodos alcanza altos niveles de infestación en áreas donde no se implementa el sistema de rotación (Smith et al. 1997). Las plagas agrícolas como Globodera spp han tratado de ser controladas durante años mediante el empleo de plaguicidas químicos de fuerte impacto negativo sobre los organismos benéficos presentes en el suelo, medio ambiente y ser humano, pero hoy día se conoce que existen muchas opciones como el uso de hongos y organismos en el manejo de plagas en el cultivo de la papa (Crozzoli 1994).

Las cifras de importación y uso de plaguicidas en Costa Rica nos muestran un panorama alarmante en cuanto a la intensidad de su uso. Entre los años 1977-79 se importaron 2,7 millones de kilogramos de plaguicidas con potencial cancerígeno, 465764 con potencial teratogénico y 230000 con potencial mutagénico, 553000 fitotóxicos, 1700000 espermatogénicos y 1800000 no especificado, mientras que para 1980-2001 se importaron un promedio de $4300000 \mathrm{~kg}$ de plaguicidas de uso restringido (García 1997).

En la literatura se mencionan varios organismos (hongos, bacterias, protozoarios y virus) que pueden ser utilizados por agricultores, y en algunos casos, ya están siendo aplicados. La alternativa de usar hongos y bacterias para el manejo de nematodos fitoparásitos puede ser una opción biológica muy importante, de actualidad (Piedra 2008). En el siglo XIX se descubrió que el hongo Arthrobotrys es un hongo que atrapa nematodos fitoparásitos (López-Llorca y Jansson 2001), además se han encontrado otros hongos que parasitan quistes de nematodos de forma natural entre ellos: Verticillium chlamydosporium (syn. Pochonia chlamydosporia) y Paecilomyces lilacinus (Holgado y Crump 2003). En México un $3,3 \%$ de quistes de Globodera rostochiensis provenientes de campos cultivados con papa, se han encontrado parasitados de forma natural con hongos como: Acremonium incrustatum, Chaetomium crispatum, Drechslera spicifer, Fusarium ventricosum, Phialophora malorum, Aspergillus sclerotiorum, Cladosporium osysporum, Paecilomyces carneus. (NúñezCamargo et al. 2003). En huevos de Globodera rostochiensis se han aislado los hongos Scolecobasidium constrictum, Gliocladium roseum y Phoma fimeti y de quistes Botryotrichum piluliferum (Trifonova y Karakjova 2003). Luego de la aplicación en campo de $10 \mathrm{~kg} / \mathrm{ha}$ de Paecilomyces lilacinus a una concentración de $7 \times 10^{8}$ unidades formadoras de colonias/g, los 45 días después de la siembra, se obtuvo una reducción de $68,2 \%$ en la penetración de estadios inmaduros de Globodera pallida en raíces de papa (Seenivasan et al. 2007).

La investigación nacional debe incursionar fuertemente en el manejo integral de los cultivos donde se disminuya el uso de agroquímicos y los productos biológicos sean incluidos en dicho plan de manejo, con la intención de que la agricultura sea más amigable con el entorno, sin detrimento de la productividad. Este estudio pretendió encontrar hongos, que tengan un efecto sobre el nematodo formador del quiste de la papa, a fin de que sean una alternativa potencial a ser usada dentro del manejo integrado, manteniendo las poblaciones de nematodos por debajo de umbrales económicos y disminuir o evitar el uso de plaguicidas sintéticos formulados. 


\section{MATERIALES Y MÉTODOS}

El presente estudio fue realizado en el Laboratorio de Servicios de Fitoprotección del INTA situado en la provincia de San José, cantón Central, distrito de Mata Redonda, durante el año 2010. Se utilizó un aislamiento de Trichoderma spp, proveniente de suelo recolectado en la Estación Experimental Carlos Durán ubicado en la provincia de Cartago, cantón Oreamuno, distrito Potrero Cerrado; un aislamiento de Beauveria bassiana proveniente del cantón de Naranjo, provincia de Alajuela, un aislamiento de Arthrobotrys spp, el cual fue aislado de un quiste de Globodera spp parasitado de la misma finca y Paecilomyces lilacinus de origen comercial.

Los quistes de Globodera spp utilizados en el estudio provenían del suelo de una misma finca, ubicada en la zona alta de la provincia de Cartago a 3300 msnm. Dada la gran cantidad de quistes que se encontraron en el suelo se seleccionaron aquellos con características semejantes en tamaño y color (Figura 1). De los mismos quistes seleccionados se obtuvo una viabilidad total de 232 huevos/quiste. La acción de los hongos sobre los huevos contenidos en los quistes fue evaluada en placas petri de 94X15 mm.

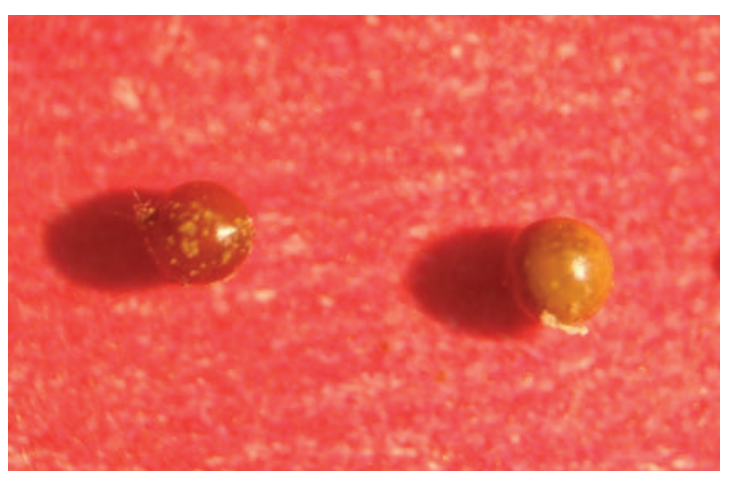

Figura 1. Quistes de Globodera spp aislados, clasificados y seleccionados de suelo. (Aumento 10X). San José, Costa Rica. 2010.

\section{Extracción de quistes de Globodera spp}

Se tomaron muestras de suelo de zonas productoras de papa de la Región Central Occidental, que se encontraban en áreas infectadas con el nematodo. Las muestras se sometieron a un proceso de secado a temperatura ambiente y bajo sombra, lo que permitió aplicar la técnica de flotación (donde los quistes secos flotaron en el agua, mientras que las partículas de suelo sedimentaron). El suelo seco, se pasó por un tamiz de 60 mesh para quitar las impurezas, luego se colocó en el equipo Fenwick y posteriormente se recolectaron los quistes en un tamiz de 500 mesh, finalmente con la ayuda de una piseta se transvasaron a un balón aforado de vidrio de $250 \mathrm{ml}$. Un papel filtro se colocó sobre un embudo y se decantó el extracto con los quistes, el papel filtro con los quistes y restos orgánicos se colocó abierto en una placa petri y se secó a temperatura ambiente, seguidamente, bajo el estereoscopio se retiraron los quistes de Globodera spp y se guardaron en un vial a $10{ }^{\circ} \mathrm{C}$ hasta su uso posterior (Ruano 1999; MAG 2006).

\section{Aislamiento de hongos asociados al quiste de Globodera spp.}

Se seleccionaron 200 quistes de Globodera spp. y se desinfectaron en grupos de 50 quistes en una solución de hipoclorito de sodio al $1 \%$ por dos minutos, seguidamente se descartó el hipoclorito de sodio y se agregó agua destilada estéril, se repitió este último paso tres veces para asegurar la eliminación de todo el desinfectante. Los quistes se colocaron en una placa petri con papel absorbente estéril para absorber el exceso de agua.

Se tomaron 100 quistes desinfectados y se colocaron en grupos de 10 por placa petri, con medio de cultivo papa dextrosa agar (PDA) con rosa de bengala a una concentración de $0,04 \mathrm{~g} / \mathrm{L}$. Los otros 100 quistes se colocaron en grupos de 10 por placa de petri con medio 
de cultivo PDA acidificado. Las placas se incubaron a temperatura ambiente $y$ se evaluaron diariamente durante 20 días, para detectar la presencia de hongos, los hongos que crecieron se aislaron y mantuvieron en tubos inclinados y placas con PDA acidificado, para su identificación y posterior utilización en el ensayo.

\section{Aislamiento de hongos asociados a huevos (hv) o estadios juveniles (j2) de Globodera spp.}

Se seleccionaron 200 quistes los cuales se desinfectaron en grupos de 50 , en una solución de hipoclorito de sodio al $1 \%$ por dos minutos, se descartó seguidamente el hipoclorito de sodio y se agregó agua destilada estéril, se repitió este último paso tres veces para asegurar la eliminación de todo el desinfectante.

Los quistes se colocaron en un homogeneizador de quistes previamente esterilizado, y fueron macerados con el fin de liberar los hv y j2 contenidos en los mismos. Con la ayuda de agua destilada estéril, el macerado se transvasó en su totalidad a tubos de vidrio estéril y se centrifugaron durante 4 min a $4000 \mathrm{rpm}$. El sobrenadante se descartó y se agregó una solución azucarada 2,5 molar y se centrifugó por 3 min a 4000 rpm, con el fin de separar los hv y j2 de los restos de la cutícula del quiste (los hv y j2 quedaron en el sobrenadante) (Cordero y Acevedo 2000).

El sobrenadante se pasó por un tamiz de 500 mesh, se lavó con agua destilada estéril y se recuperaron los hv y j2 en un tubo estéril con capacidad para $20 \mathrm{ml}$.

Para desinfectar los hv y j2 obtenidos, la solución se centrifugó y se eliminó el sobrenadante, se agregaron $10 \mathrm{ml}$ de hipoclorito de sodio al $0,5 \%$ se dejó reposar por 30 segundos y se centrifugó a 4000 rpm por 2 min, se eliminó el desinfectante y se agregó agua destilada estéril. Se agitó y se centrifugó por 2 min a 4000 rpm, este último paso se realizó dos veces más, con el fin de eliminar completamente el desinfectante. Luego de la desinfección, se suspendieron los hv y j2 en $2 \mathrm{ml}$ de agua destilada estéril (Cordero y Acevedo 2000). Un volumen de 0,2 $\mathrm{ml}$ de la suspensión de hv y j2 se inoculó en 10 placas petri con PDA más rosa de bengala y en 10 placas de petri con PDA acidificado. Se incubaron las placas a temperatura ambiente y se evaluaron diariamente durante 15 días; los hongos detectados se aislaron en tubos inclinados y en placas PDA acidificado para su posterior identificación y utilización en el ensayo.

\section{Prueba in vitro de hongos versus Globodera spp}

En placas petri con medio de cultivo PDA acidificado, se colocó un disco con el hongo a evaluar, conjuntamente con tres discos con medio de cultivo Agar Agua (AA) con un quiste cada uno (previamente desinfectados con hipoclorito de sodio al $0,5 \%$ ), la equidistancia entre discos fue de aproximadamente $3 \mathrm{~cm}$. Se realizaron cinco réplicas de cada hongo a estudiar y de un tratamiento testigo sin hongo. Los platos fueron incubados a temperatura ambiente y se evaluaron diariamente hasta por 20 días. La evaluación del parasitismo, se realizó después de dos días de que se observó crecimiento del hongo sobre el quiste.

Para determinar el porcentaje de parasitismo, los hv y j2 de los quistes se maceraron para liberar los estadios inmaduros y bajo un microscopio de luz, se realizó la determinación del crecimiento de hongos dentro de dichos estadios.

\section{Diseño experimental}

Se utilizó un diseño de bloques completos al azar con cinco tratamientos y cinco repeticiones para un total de 25 unidades experimentales. Los tratamientos utilizados fueron: 


\begin{tabular}{|l|l|}
\hline $\mathrm{N}^{\circ}$ & \multicolumn{1}{|c|}{ Tratamiento } \\
\hline 1 & B.bassiana + quistes \\
\hline 2 & P. lilacinus + quistes \\
\hline 3 & Trichoderma spp + quistes \\
\hline 4 & Hongo 10 (Arthrobotrys spp) + quistes \\
\hline 5 & Quistes sin hongos \\
\hline
\end{tabular}

\section{Unidad experimental y variable a evaluar}

Se consideró como unidad experimental, cada placa petri con medio de cultivo PDA conteniendo los tres discos con un quiste cada uno y un disco con el tratamiento. Para la determinación del porcentaje de parasitismo, en cada unidad experimental se evaluó bajo el microscopio de luz, 300 estadios juveniles (100 por cada quiste tratado). Se determinó los estadios parasitados y no parasitados.

Se realizó un análisis de varianza para la variable de estudio a fin de determinar la existencia de diferencias estadísticamente significativas entre los promedios de los tratamientos. Se realizó una comparación de medias mediante la prueba Duncan con un nivel de significancia de 0,05 . Se utilizó el programa estadístico InfoStat versión 2008 (UNC 2008).

El modelo estadístico para el arreglo de tratamientos fue el siguiente:

Donde:

$$
Y_{i j}=\mu+T_{i}+E_{i j k .}
$$

$Y_{i j}=$ Variable respuesta

$\mu=$ Media poblacional

$\mathrm{T}_{\mathrm{i}}=$ Efecto del i-ésimo tratamiento

$E_{i j k}=$ Término de error experimental, supuestamente con distribución normal con media cero y varianza constante.

\section{RESULTADOS Y DISCUSIÓN}

La población de quistes que se obtuvo mostró la presencia en suelo de nematodos de los géneros Heterodera, Punctodera $y$ Globodera. La diversidad de hongos aislados de los quistes y estadios juveniles fue mayor de la esperada, lo que probablemente se debe a la existencia en la zona de muestreo de una actividad parasítica natural por hongos. En total se logró aislar 12 diferentes hongos asociados al quiste y nueve a los estadios inmaduros (hv y j2) de Globodera spp (Figura 2). Probablemente no todos los hongos aislados representan actividad nematicida. Dadas las limitaciones en la identificación de los mismos, en este estudio únicamente se utilizó un hongo aislado de estadios inmaduros, del género Arthrobotrys spp al cual se le han descrito sus capacidades nematicidas. El resto de hongos aislados se mantienen en colección para futuros estudios.
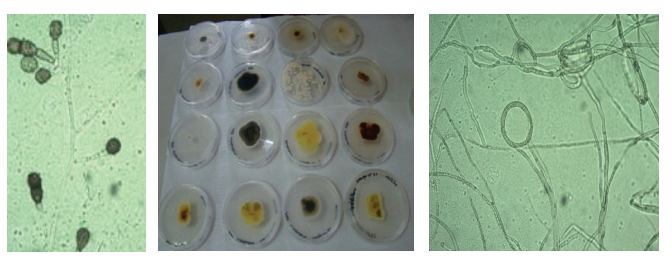

Figura 2. Hongos aislados de quistes y estadios juveniles del nematodo Globodera spp. San José, Costa Rica. 2010.

El porcentaje de parasitismo fue evaluado en el microscopio de luz. Las variaciones, alteraciones, deformidades en las estructuras normales del huevo o estadio juvenil y la presencia de micelio o estructura fúngica fueron tomadas como parasitismo positivo. En la Figura 3 se observa un estadio juvenil no parasitado el cual mantiene su forma y muestra todas sus estructuras sin alteraciones ya sea que se encuentre dentro del huevo o libre dentro del quiste. 


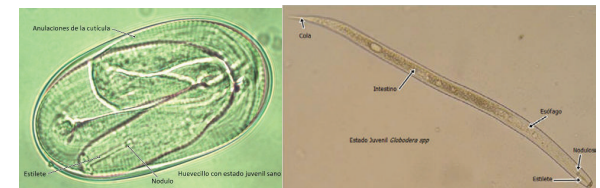

Figura 3. Estadio juvenil de Globodera spp no parasitado fuera y dentro del huevo. (Aumento 40X). San José, Costa Rica. 2010.
Al evaluar el grado de parasitismo se observó el efecto del hongo sobre los hv y j2 dentro del quiste, en algunos casos se notaron deformidades en la epidermis del nematodo; en otros la epidermis se mantenía intacta, sin embargo, no se visualizaban los órganos internos y en algunas observaciones el nematodo fue totalmente consumido por el hongo el cual llegó a ocupar todo el espacio dentro del mismo (Figura 4).

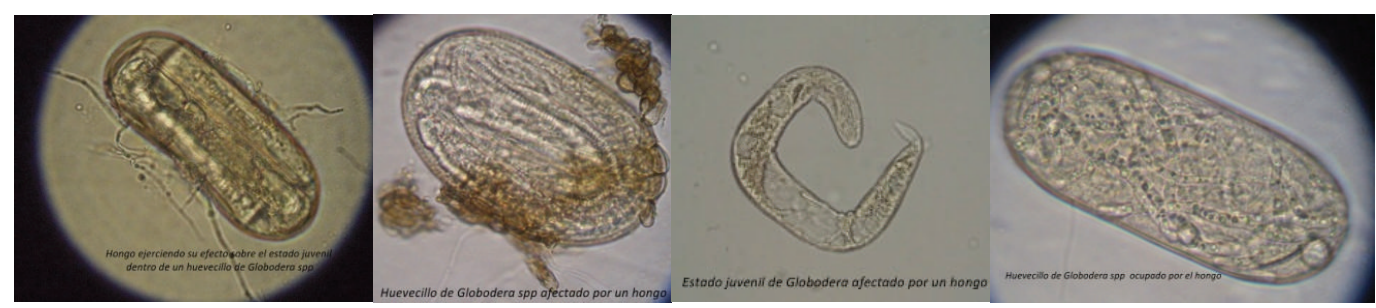

Figura 4. Hongos ejerciendo un efecto nematicida sobre estadios juveniles dentro del quiste de Globodera spp. (Aumento 40X). San José, Costa Rica. 2010.

En la Figura 5, se observan los valores de parasitismo de quistes de Globodera spp expuestos a cuatro hongos diferentes. Se presentaron diferencias estadísticas altamente significativas $(P=0,0001)$ entre los tratamientos evaluados para la variable porcentaje de parasitismo; el coeficiente de variación fue bajo $6,31 \%$ y un coeficiente de determinación $\mathrm{R}^{2}$ de $98 \%$, lo cual demostró que los datos se mantuvieron muy homogéneos entre sí para la variable evaluada. Todos los tratamientos evaluados superaron estadísticamente al testigo. Los hv y j2 del nematodo dentro del quiste, fueron parasitados en un $97 \%$ por Paecilomyces lilacinus, diferenciándose estadísticamente con el testigo y los demás tratamientos excepto con Beauveria bassiana, le siguen en orden decreciente, pero siempre con un alto porcentaje de parasitismo, Beauveria bassiana con un $93,6 \%$, Trichoderma sp con un $88,2 \%$ y por último el tratamiento hongo 10 (Arthrobotrys spp) con un $86,7 \%$. Todos los tratamientos ejercieron un efecto control sobre los estadios juveniles dentro del quiste de Globodera spp.

Los tratamientos con Beauveria bassiana, Trichoderma spp y Arthrobotrys sp no mostraron diferencias estadísticas entre sí, pero sí se diferenciaron respecto al testigo. El tratamiento sin hongo (testigo) presentó un porcentaje de parasitismo de $13,3 \%$ lo cual se explica probablemente por la existencia de un parasitismo natural no determinado en este ensayo. 


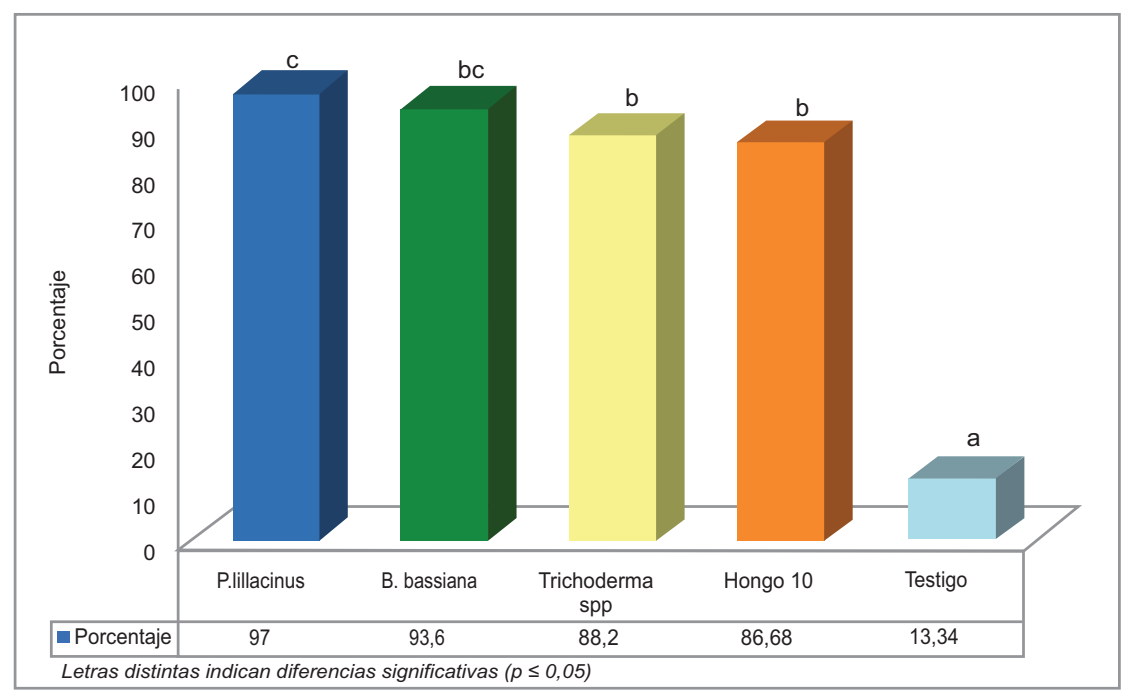

Figura 5. Porcentaje de parasitismo de cuatro hongos sobre estadios juveniles de Globodera spp. San José, Costa Rica. 2010.

Con este estudio se demuestra que existen hongos nematófagos para su implementación en programas de control biológico para el manejo del nematodo formador del quiste de la papa (Globodera spp), los cuales pueden ser utilizados para contribuir en la reducción del uso de plaguicidas sintéticos formulados. Sin embargo los hongos utilizados deben ser estudiados y evaluados en condiciones de campo a fin de validar su efectividad en ese ambiente.

\section{LITERATURA CITADA}

Cordero, M.; Acevedo, R. 2000. Evaluación de la capacidad de parasitismo de hongos asociados con el nematodo quiste de la papa, Globodera spp. Universidad de Táchira, Laboratorio de Nematología Agrícola y Laboratorio de Control Biológico. Venezuela. p. 3-4.
Cozzoli, R. 1994. Temas de nematología Agrícola I. Universidad Central de Venezuela, Facultad de Agronomía, Comisión de información p. 8-9.

García, J. 1997. Introducción a los plaguicidas. Editorial UNED. San José, CR. p. 233-264.

Holgado, R.; Crump, D. 2003. First record on the occurrence of nematophagous fungi parasitizing cyst nematodes in Norway. International Journal of Nematology 13(1): 6571.

López-Llorca, L.; Jansson, H-B. 2001. "Biodiversidad del suelo: control biológico de nematodos fitopatógenos por hongos nematófagos". Universidad de Alicante. Cuadernos de biodiversidad. No. 6, p. 12-15

MAG (Ministerio de Agricultura y Ganadería). SFE (Servicio Fitosanitario del Estado). 2006. Plan de acción del nematodo blanco del quiste de la papa. Globodera pallida_stone. pp: 1., 
21-23. (en línea). Consultado 10 set. 2010. Disponible en: http://www.protecnet.go.cr.

Núñez-Camargo, M del C.; Carrión, G.; Nuñez-Sánchez, A. 2003. Fungi associated with Globodera restochiensis cysts in México. International Journal of Nematology 13 (2): 151-161.

Piedra, R. 2008. Manejo biológico de nematodos fitoparásitos con hongos y bacterias. Rev Tecnología en marcha. Instituto Tecnológico de Costa Rica. Editorial Tecnológica de Costa Rica. p. 123-132.

Ruano, B. 1999. Evaluación de las poblaciones de nematodos (Globodera spp) en patata en Mallorca. Consejería de Economía, Agricultura, Comercio e Industria Palma de Mallorca. p. 59-60.

Seenivasan, N.; Devrajan, K.; Selvaraj, N. 2007. Management of potato cyst nematodes, Globodera spp. Through biological control. Indian Journal of Nematology 37 (1):27-29.

Smith, I.M.; McNamara, D.G.; Scott, P.R.; Holderness, M.; 1997. Globodera rostochiensis and Globodera pallida Data Sheets on Quarantine Pests. p. 601-606. En: Quarantine Pest for Europe. 2 ed. CAB International \& EPPO.UK $1425 \mathrm{p}$.

Trifonova, Z.; Karakjova, J. 2003. Fungal parasitism of the cysts and eggs of the Globodera rostochiensis. Journal of Agricultural Sciences, Belgrade 48(1):103-110.

Trifonova, Z. 2006. Potato cyst nematode (Globodera pallida) (Stone, 1973, Berhrens, 1975. Selskostopanska Nauka (Agricultural Science) 39 (6):54-64.

UNC (Universidad Nacional de Córdoba, AR). 2008. Programa InfoStat: Sofware de Estadística y Biometría. 